\title{
Residual stress analysis, mechanical and metallurgical properties of dissimilar weldments of Monel 400 and AISI 316
}

This research manuscript explores the residual stress analysis, mechanical and metallurgical aspects of dissimilar welded joints between AISI 316 and Monel 400 developed by constant, pulse and Interpulse current TIG welding processes. The induced residual stresses have been measured experimentally by employing X-ray diffraction. The mechanical properties of welded joints have been determined by conducting tensile and Vickers hardness testing. The metallurgical properties of weldments have been analyzed by employing optical and scanning electron microscopy. From the experimental results, lower residual stresses have been observed in Interpulse current TIG weldment than the other two weldments. The tensile properties of the Interpulse current TIG weldment were observed to be higher than the other two weldments. In Interpulse TIG weldments, grain refinement and reduced heat affected zone near the fusion zone have been observed.

Keywords: Constant current TIG welding; Pulsed current TIG welding; Interpulse current TIG welding; Mechanical properties; Metallurgical properties

\section{Introduction}

$\mathrm{Ni}-\mathrm{Cu}$ based alloy, Monel 400, is extensively used in various corrosive environments because it is resistant to stress corrosion cracking and also contributes to good cracking resistance under tensile loading conditions $[1,2]$. This al- loy has applications in marine industries, chemical processing equipment and boiler feedwater heaters. Similarly, 316 grade steels convey superior properties when exposed to cryogenic temperature, pitting and crevice corrosion [3]. Dissimilar welded joints of austenitic steel 316 and Monel 400 are extensively used in boilers and feed water heaters, nuclear, petrochemical and offshore industries where the welding roots are exposed to high pressure and hot corrosive environments $[4,5]$. The resulting welded joints of dissimilar plates are really cumbersome to achieve and a challenging task because of their different chemical composition, phase structures and differences in thermal properties. During joining of dissimilar metals, the choice of filler metal plays a key role so as to suit both the base metals. The alloying elements of filler wire can influence phase formation, grain boundaries and the bead geometry, which further influence the mechanical behavior and the formation of hot cracks $[6,7]$. Devendranath et al. [8] reported the effect of fillers on similar welding joint of AISI904L developed using the pulsed current tungsten inert gas welding (TIG) technique. The results indicate that the ERNiCrMo-14 filler weldment exhibited better mechanical and corrosion properties than the other two fillers ERNiCrMo-14 and ERNiCu-7 weldments. Nibased filler wire is most suitable for the dissimilar joint of Monel 400 and austenitic stainless steels [9].

In the TIG welding process, uneven expansion and contraction occurs due to the heating and rapid cooling cycles, resulting in development of thermally induced residual 
stresses (RS). These developed stresses remain within a welded component when external applied loads are removed [10]. The X-ray diffraction (XRD) method, one of the non-destructive techniques (NDT), is most suitable to measure the RS for welded structures [11]. This method is proven and useful for the determination of macro- and micro-RS and also capable of giving useful information about sub-micro stresses [12]. The magnitude and distribution of RS in welded structures mainly depends on total heat inputs, cooling rates and properties of base metals. In constant current TIG welding, a high level of thermal energy is continuously given to the base plates which leads to enlargement of the weld pool and heat affected region $[13,14]$. Due to these uneven thermal cycles in the vicinity of the weld zone, expansion and sudden contraction takes place which leads to development of high RS [15]. Vasantharaja et al. [16] reported the effect of TIG and Activated-TIG welding on development of RS and distortions in similar joints of steel grade 316LN. Peak tensile RS and distortions are observed to be lower in A-TIG welding compared to those of TIG welded joints. Kohandeghan et al. [17] studied the residual stress development of AA5251 of TIG weldments and concluded that the magnitude of RS affects the mechanical properties and particularly in the heat affected zone (HAZ). Zhang et al. [18] studied the distribution of RS in Ni-based alloys by using $\mathrm{XRD}$ and neutron techniques. The cooling rates are proved to be a key parameter to induce the stresses in weldments. Ahmed et al. [19] investigated the development of RS in martensitic steels using XRD. Compressive RS are beneficial for the applications where weldments are susceptible to stress corrosion by closing the cracks. The RS distribution in the long length weldments mainly depends on welding segmental time. In these weldments the pre-heating effect can be caused due to the time lag between successive welding segmental times. The starting of the segmental welds mitigates the RS [20]. The thermal properties of base metals are also effect the development of RS during joining of dissimilar plates. Tapes et al. [21] measured the RS in dissimilar joints of AA5051 and AA6061 by using XRD. The maximum longitudinal and transverse stresses were observed in AA6061 than the AA5052. Murugan et al. [22] measured the RS in low carbon steel and SS 304 weldments by using XRD. The stress distribution is found to be more in SS 304 than low carbon steels after the first pass. However, the stress distribution is higher in low carbon steels after finishing all welding passes than the stainless steels. Ranjbarnodeh et al. [23] investigated the total heat input rates on development of RS in AISI 409 and carbon steel CK4. The higher RS are observed in plain carbon steel because of lower elastic modulus than the ferritic steels. Also, as the yield strength of carbon steel is higher, it offers resistance against the contraction during cooling resulted in development of RS. The distortions in weldments develop because of sudden shrinkage due to uneven heating and cooling cycles that results in misalignment and gaps between the base plates [24, 25].

The heat input rates significantly affect the development of the weld bead and its characteristic constituents' microstructure, HAZ and weld zone. Pandit et al. [26] investigated the metallurgical evaluation of TIG weldments between Monel 400 and C-276 using ERNiCrMo-3 filler wire. The results indicated that coarse grains are formed at the HAZ of both the plates due to constant heat inputs. Coarse grains and segregation of alloying elements are formed near the HAZ of Monel 400 when TIG welding is employed for joining of Monel 400 and AISI 304 [27]. Micro-segregation of filler elements such as $\mathrm{Cu}$ and $\mathrm{Cr}$ occur near the weld interface in the dissimilar welds of AISI 304 and Monel 400 when TIG welding is employed. Continuous heat input rates in the TIG welding technique have caused the formation of secondary phases and micro-segregation of filler alloying elements, thus causing an overall reduction in quality of welds [28, 29]. Current being the main parameter to determine the heat input rates and arc characteristics, the arc current can be made to pulsate from low to high levels current for a given set of pulse frequencies by using pulse TIG welding technique. Some metallurgical improvements can be achieved by using pulse TIG welding, such as grain refinement, and improvement in mechanical behavior of weldments $[30,31]$. Dev et al. [32] developed dissimilar welded joints between Inconel 718 and AISI 416 with pulsed TIG welding to study the metallurgical behavior. Lower segregation of alloying elements and reduced coarse grains are observed in pulse TIG welding process. Lower segregation of filler elements and reduced partially mixed zone are attained when pulse TIG welding is employed to join C-276 and Monel 400 [33]. Reddy et al. [34] developed pulse TIG aluminum welded joints to study the effect of pulse current on bead and thermal profiles. Grain refinement was observed in this welding process with enhanced tensile properties.

The Interpulse TIG welding technique uses high pulse frequency $(20 \mathrm{kHz})$ modulation and a magnetic field to improve constricted welding arc characteristics which control the heat input rates [35]. This welding technique involves three different types of current, namely, main current, delta current and background current. The main current is the maximum weld current which can be used alone for straight arc mode to attain full penetration. The low current (background current) is used to maintain the arc stability during pulse arc mode. The pulse arc effect can be noticed if a higher difference is maintained between the main and background current. The delta current is used to generate precise electromagnetic force to constrict the welding arc to maintain a

Table 1. Chemical composition (by wt.\%) of filler/base metals.

\begin{tabular}{|c|c|c|c|c|c|c|c|c|c|}
\hline Filler/base metal & $\mathrm{Ni}$ & $\mathrm{Cr}$ & $\mathrm{Fe}$ & $\mathrm{Cu}$ & $\mathrm{Mn}$ & $\mathrm{Mo}$ & $\mathrm{Si}$ & $\mathrm{C}$ & Others \\
\hline ERNiCrMo-3 & 58.95 & 21.5 & 5.0 & 0.5 & 0.5 & 9.0 & 0.5 & 0.1 & Nb-3.13, Al-0.4, Ti-0.42 \\
Monel 400 & 65.15 & $\mathrm{Nil}$ & 1.25 & 32 & 1.0 & $\mathrm{Nil}$ & 0.5 & 0.1 & Nil \\
AISI 316 & 10.6 & 17.6 & 66.41 & $\mathrm{Nil}$ & 2.0 & 2.5 & 0.8 & 0.08 & $\mathrm{P}-0.004$ \\
\hline
\end{tabular}


B. Yelamasetti, G. Rajyalakshmi: Properties of dissimilar weldments of Monel 400 and AISI 316

Table 2. Welding parameters of constant, pulsed and Interpulse current TIG welding techniques.

\begin{tabular}{|c|c|c|c|}
\hline Parameters & Constant-TIG & Pulsed-TIG & Interpulse-TIG \\
\hline Main current $\left(I_{\mathrm{m}}\right)$ & $135 \mathrm{~A}$ & $180 \mathrm{~A}$ & $175 \mathrm{~A}$ \\
Delta current $\left(I_{\mathrm{d}}\right)$ & - & - & $140 \mathrm{~A}$ \\
Background current $\left(I_{\mathrm{b}}\right)$ & - & $90 \mathrm{~A}$ & $110 \mathrm{~A}$ \\
Arc Voltage $(V)$ & $14 \mathrm{~V}$ & $14 \mathrm{~V}$ & $14 \mathrm{~V}$ \\
Pulse frequency $\left(P_{\mathrm{f}}\right)$ & - & $4 \mathrm{~Hz}$ & - \\
Heat input rate $(Q)$ & $0.619 \mathrm{~kJ} \mathrm{~mm}^{-1}$ & $0.619 \mathrm{~kJ} \mathrm{~mm}^{-1}$ & $0.619 \mathrm{~kJ} \mathrm{~mm}^{-1}$ \\
\hline
\end{tabular}

stiff, narrow welding arc during delta mode. This allows improved heat input rates on welds that are critical to achieving full penetration. The weldments of Ti-alloys produced by the Interpulse TIG welding technique are successful and the bead development and microstructures are similar to the plasma welding arc process [36]. Interpulse TIG welding can achieve controlled heat energy, reduced heat affected region and reduced RS in the vicinity of the fusion zone [37].

In this research, constant, pulsed and Interpulse current TIG welding techniques were used to join the dissimilar metals AISI 316 and Monel 400. Heat input rates and filler wires were the same in the three welding methods. The effect of variations in TIG welding current on development of RS in dissimilar welded joints were studied and compared. Further, mechanical behavior and metallurgical properties of the welded joints were studied.

\section{Experimental details}

\subsection{Base/filler metals}

The base metals, AISI 316 and Monel 400 with the size of $120 \times 80 \times 5 \mathrm{~mm}$ were considered for the development of dissimilar welded joints using constant current TIG, pulsed current TIG and Interpulse current TIG techniques. The chemical compositions in wt.\% of the filler and base metals are given in Table 1. Standard butt V-groove configuration was made on the base metals to fill the $5 \mathrm{~mm}$ thick plates using ERNiCrMo-3 filler wire of $1.6 \mathrm{~mm}$ diameter. For maintaining a uniform root gap between base metals along the length of the joint, tack welding was conducted at the ends as well as middle of the joint. The welding parameters of the three welding methods listed in Table 2 were set before the joining of dissimilar metals. The heat input rate values of three TIG welding techniques were calculated by using Eq. (1). During the welding process, back purging gas and shielding gas were maintained to prevent weld zone contamination. The developed dissimilar joints are shown in Fig. 1

$Q_{\mathrm{TIG} / \text { pulse TIG/Interpulse TIG }}=\frac{\eta \times V \times I / I_{\mathrm{avg}} .}{v}$

$I_{\text {avg. }}=\frac{I_{\mathrm{b}} \times T_{\mathrm{b}}+I_{\mathrm{m}} \times T_{\mathrm{m}}}{T_{\mathrm{b}}+T_{\mathrm{m}}}$

$I_{\text {avg. }}=\frac{\left(I_{\mathrm{m}}+I_{\mathrm{d}}\right) / 2+\left(I_{\mathrm{b}}+I_{\mathrm{d}}\right) / 2}{2}$

Where, $\eta=$ arc efficiency $(\eta=60 \%)[38,39], Q=$ heat input rates, $\mathrm{kJ} \mathrm{mm}^{-1} ; I_{\mathrm{m}}=$ main current, A; $I_{\mathrm{d}}=$ delta current, A; $I_{\mathrm{b}}=$ background current, A; $T_{\mathrm{b}}=$ background current time, $\mathrm{s}$ and $T_{\mathrm{m}}=$ main current time, $\mathrm{s}$.

The average welding current $\left(I_{\text {avg. }}\right)$ of pulsed and Interpulse current TIG welding techniques is calculated from Eqs. (2) \& (3), respectively.

\subsection{Specimen preparation and testing}

After welding, the welded samples were inspected using Xray radiography testing (XRT) to determine any defects in dissimilar welded joints. In this research, a CEREM XRT machine was employed. After XRT analysis, residual stresses were measured experimentally using XRD. In this XRD technique, X-rays measure only the surface strains and from this the stresses are calculated using the $\sin ^{2} \psi$ method (discussed in Section 3). After XRT and RS analyses, the weld-

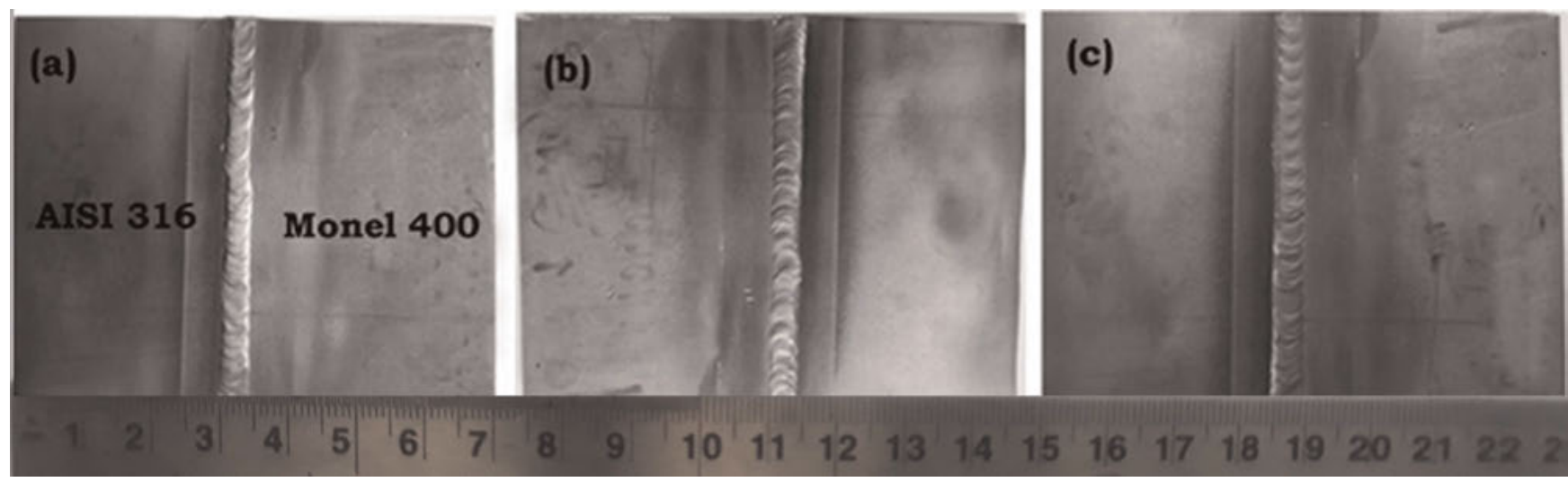

Fig. 1. Dissimilar joints of AISI 316 and Monel 400 joined by (a) Constant TIG, (b) Pulse TIG, (c) Interpulse TIG techniques. 
ments were sliced transversely, i.e., perpendicular to the welding direction into different welding coupons to determine the mechanical and metallurgical properties. The tensile properties of weldments were determined by conducting a tensile test on a UTM machine as per the ASTM E/8 protocol. The microhardness values of weldments were measured with a Vickers hardness tester by setting the load with $100 \mathrm{gf}$ for a constant dwell time of $10 \mathrm{~s}$. The welding coupon of size $50 \times 5 \times 5 \mathrm{~mm}$ was polished with different emery papers coated with silicon carbide particles. Marble's reagent was used at the HAZ and base plate of Monel 400 and fusion zone, whereas a combination of $10 \mathrm{cc}$ $\mathrm{HNO}_{3}, 15 \mathrm{ml} \mathrm{HCl}$ and $10 \mathrm{ml} \mathrm{CH} \mathrm{CHOH}_{3} \mathrm{CO}$ wased on the HAZ and base plate of steel 316 . The microstructures of polished welding coupons were analyzed using scanning electron microscops (SEM) and optical microscops (OM). The chemical composition of the welded joints across the fusion zone and HAZ of base plates were analyzed using energy dispersive X-ray analysis (EDAX) in different zones.

\section{XRD technique for residual stress measurement}

The XRD technique involves change in the inter-planar spacing of a stressed specimen which can provide information on RS. The angle of reflection is selected to measure the change in the lattice inter-planar spacing by comparing the same with a stress-free sample that in turn is used to measure the sum of the principal stresses on the weld surface by using Bragg's law Eq. (4). The peaks refer to the layer in the specimen whose plane follows Bragg's law at a certain angle of incident of X-rays.

$n \lambda=2 d \sin \theta)$

Where, $n=$ order of reflection; $d=$ planar space between two lattices; $\lambda=\mathrm{X}$-ray wavelength $(\AA)$; and $\theta=$ angle between reflected planes and incident beam.

The welded sample was placed on the workbench of the XRD testing machine after electro chemical polishing. The surface under examination was mounted in the para-focusing position whenever possible in order to obtain sharp diffraction peaks. The radiation source vanadium filtered $\mathrm{Cu}-\mathrm{K}_{\alpha}$ was used as it suited both the base metals, which have the same ' $h k l$ ' plane $\left\{\begin{array}{lll}3 & 1 & 1\end{array}\right\}$ [40]. Changes in $d$ (inter-planar spacing) lead to a shift in XRD peaks, which is taken as the measure of the RS. The RS value $\sigma_{\emptyset}$ can be calculated by substituting elastic modulus $(E)$, Poisson's ratio $(\vartheta)$, interplanar unstressed lattice space $\left(d_{\mathrm{o}}\right)$ and slope value $(m)$ in Eq. (5).

$\sigma_{\emptyset}=\frac{m}{d_{0}}\left(\frac{E}{(1+\vartheta)}\right)$

The radiation wavelength $\lambda=1.07442 \AA$ was deflected from plane (3 11 ) of the surface at $2 \theta=156.12^{\circ} \cdot \psi$-Angles were taken between $-45^{\circ}$ to $45^{\circ}$ for measuring inter-planar lattice spacing. The RS were measured at the fusion line, and on either side (including base and heat affected region) of fusion at a distance of 12 and $50 \mathrm{~mm}$, respectively. For example, the RS value in the weld zone of TIG weldment is calculated by using Eq. (5). The $m$ value which is the slope derived from the $d$ versus $\sin ^{2} \psi$ plot. The calculated RS value was found to be $189 \mathrm{MPa}$ in compressive nature.

\section{Experimental results and discussions}

\subsection{X-radiography test}

The X-ray images of welded joints of dissimilar metals are given in Fig. 2. These XRT results show that the dissimilar
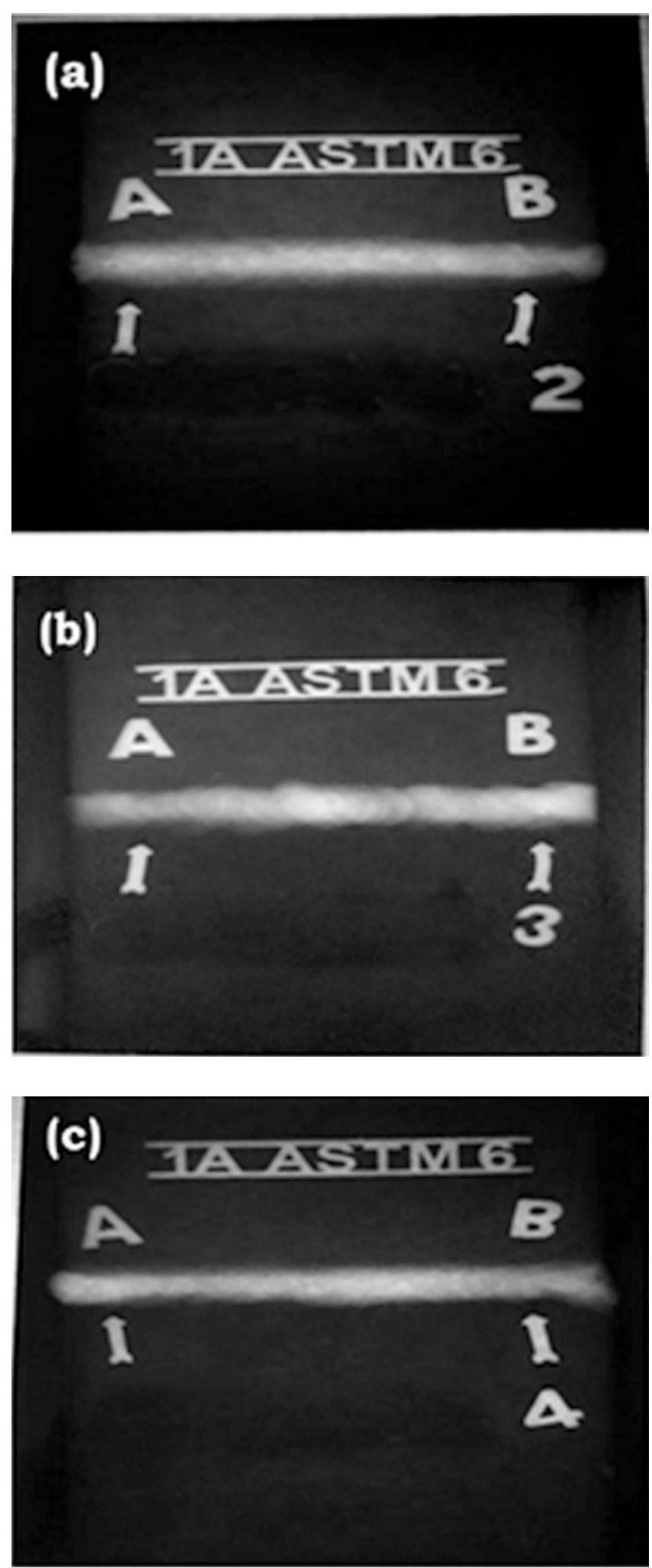

Fig. 2. XRT films of dissimilar joints joined by (a) Constant TIG, (b) Pulsed TIG, (c) Interpulse TIG techniques. 
B. Yelamasetti, G. Rajyalakshmi: Properties of dissimilar weldments of Monel 400 and AISI 316

Table 3. Residual stress (MPa) values at different locations of dissimilar weldments.

\begin{tabular}{|c|c|c|c|c|c|}
\hline \multirow{2}{*}{ Welding technique } & \multicolumn{2}{|c|}{ AISI 316 (from fusion line) } & Fusion zone & \multicolumn{2}{c|}{ Monel 400 (from fusion line) } \\
\cline { 2 - 6 } & $50 \mathrm{~mm}$ & $12 \mathrm{~mm}$ & 0 & $12 \mathrm{~mm}$ & $50 \mathrm{~mm}$ \\
\hline Constant TIG & -2.4 & -44 & -189 & 46 & 5.2 \\
Pulsed TIG & 1.2 & -47 & -101 & 35 & 2.1 \\
Interpulse TIG & 0 & 45 & -53 & 37 & 0 \\
\hline
\end{tabular}

welded joints developed using 3 welding techniques were free from surface and sub-surface defects like spatter, inclusions, porosity, etc. Uniform and complete bead profiles were observed in all the weldments.

\subsection{Residual stresses}

From the XRD analysis, the RS values of dissimilar weldments were calculated by using $\sin ^{2} \psi$ method and the calculated values are listed in Table 3 . The distributions of $\mathrm{RS}$ in welded joints of three welding techniques are shown in Fig. 3. The peak RS values, $-189 \mathrm{MPa},-101 \mathrm{MPa}$ and $-53 \mathrm{MPa}$, were observed at the fusion zones of constant, pulsed and Interpulse current TIG weldments, respectively. Due to the variations in thermal properties, especially thermal conductivity values of the base metals, the uneven expansions and contractions occurred in the vicinity of the fusion boundary, which to the development of

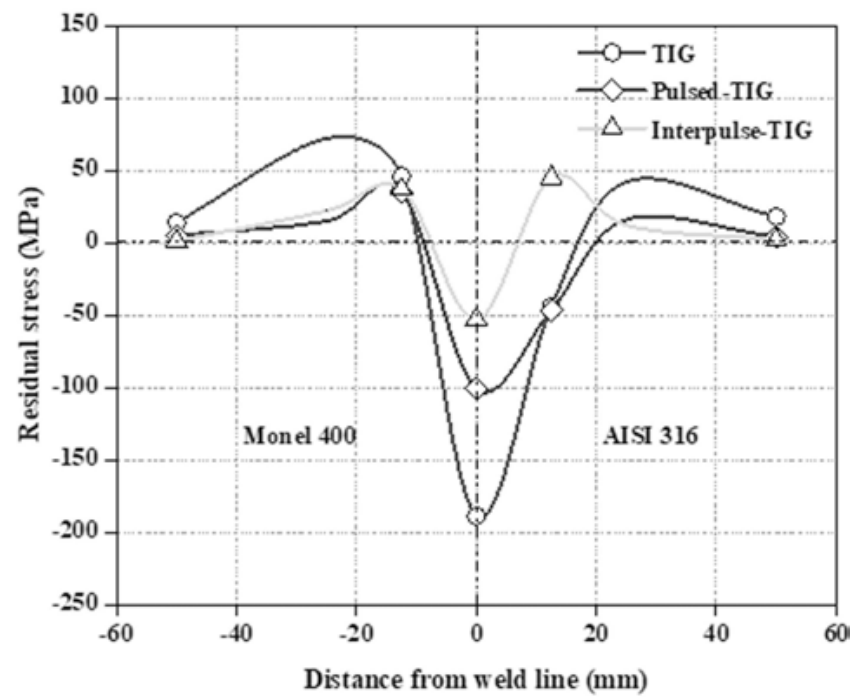

Fig. 3. Residual stress distribution along transverse direction in three welded joints. compressive stresses [37]. Due to constant heat input rates to the welded joint in TIG welding high RS were observed. The RS values near the fusion zone were lower in the other two welding techniques due to the controlled total heat inputs. In all the weldments the state of RS is then changed from compressive nature to tensile nature for further distances in the Monel 400 side. In all the welding techniques the developed RS are self-balanced in the welded structure and within the yield limits only.

\subsection{Mechanical properties}

\subsubsection{Tensile studies}

The average tensile properties of welded joints and base plates were computed by conducting tensile tests on three tensile specimens of each welded joint, and are listed in Table 4. The stress-strain plots of base metals and welded joints are shown in Fig. 4. The maximum weld strength of $586 \mathrm{MPa}$ was observed in Interpulse current TIG weldments. The yield stress of pulsed and Interpulse current TIG welded joints was observed to be higher than the con-

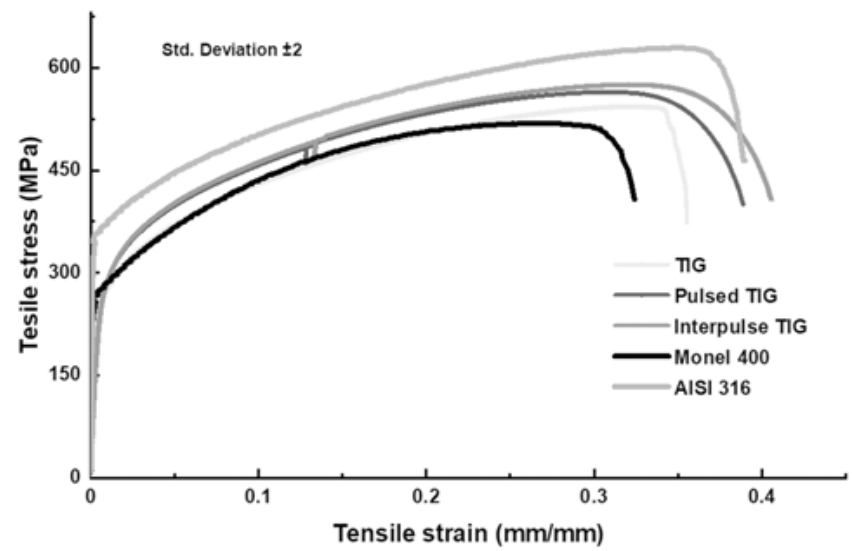

Fig. 4. Tensile stress-strain plots of base metals and dissimilar welded joints.

Table 4. Tensile properties of base plates and welded joints made of TIG, pulsed TIG and Interpulse TIG welding techniques.

\begin{tabular}{|c|c|c|c|c|c|}
\hline Base/weldment & $Y S(\mathrm{MPa})$ & UTS $(\mathrm{MPa})$ & \% Reduction in area & \% elongation & Failure location \\
\hline Monel 400 & 215 & 516 & 49 & 34 & - \\
AISI 316 & 350 & 632 & 60 & 45 & - \\
Constant-TIG & 253 & 544 & 58 & 41 & Monel 400 \\
Pulsed-TIG & 343 & 554 & 64 & 40 & Monel 400 \\
Interpulse-TIG & 356 & 586 & 60 & 33 & Monel 400 \\
\hline
\end{tabular}


stant current TIG welded joints, which could be attributed to the improvement of the factor of safety of welded joints. During tensile loading, the resistance against the applied load increased adequately at the vicinity of the weld area and the fracture occurred away from the weld zone. The ratio of yield strength $(Y S)$ to ultimate tensile strength (UTS) of pulsed and Interpulse current TIG welded joints was observed to be high when compared to both the non-welded base metals. Owing to the maximum Vickers hardness experienced in the welded zone due to $\mathrm{Ni}-\mathrm{Cu}$ rich regions perceived from EDS analysis, the failure did not occur at the fusion boundary. This failure occurred in all the welded joints in the base metal Monel 400.

\subsubsection{Hardness studies}

The Vickers hardness values were measured on welded joints and measured values are plotted in Fig. 5. The average hardness value at the fusion zone of Interpulse TIG weldment $\left(215 \mathrm{HV}_{0.1}\right)$ was observed to be greater than constant TIG weldment $\left(208 \mathrm{HV}_{0.1}\right)$ and pulse TIG weldment $\left(212 \mathrm{HV}_{0.1}\right)$. The average micro-hardness value at the HAZ of AISI 316 was slightly decreased when employing constant current TIG welding and its EDS result showed the formation of low density alloying elements in HAZ. The hardness value at the heat affected region of base metal Monel 400 was improved in pulse and Inter-
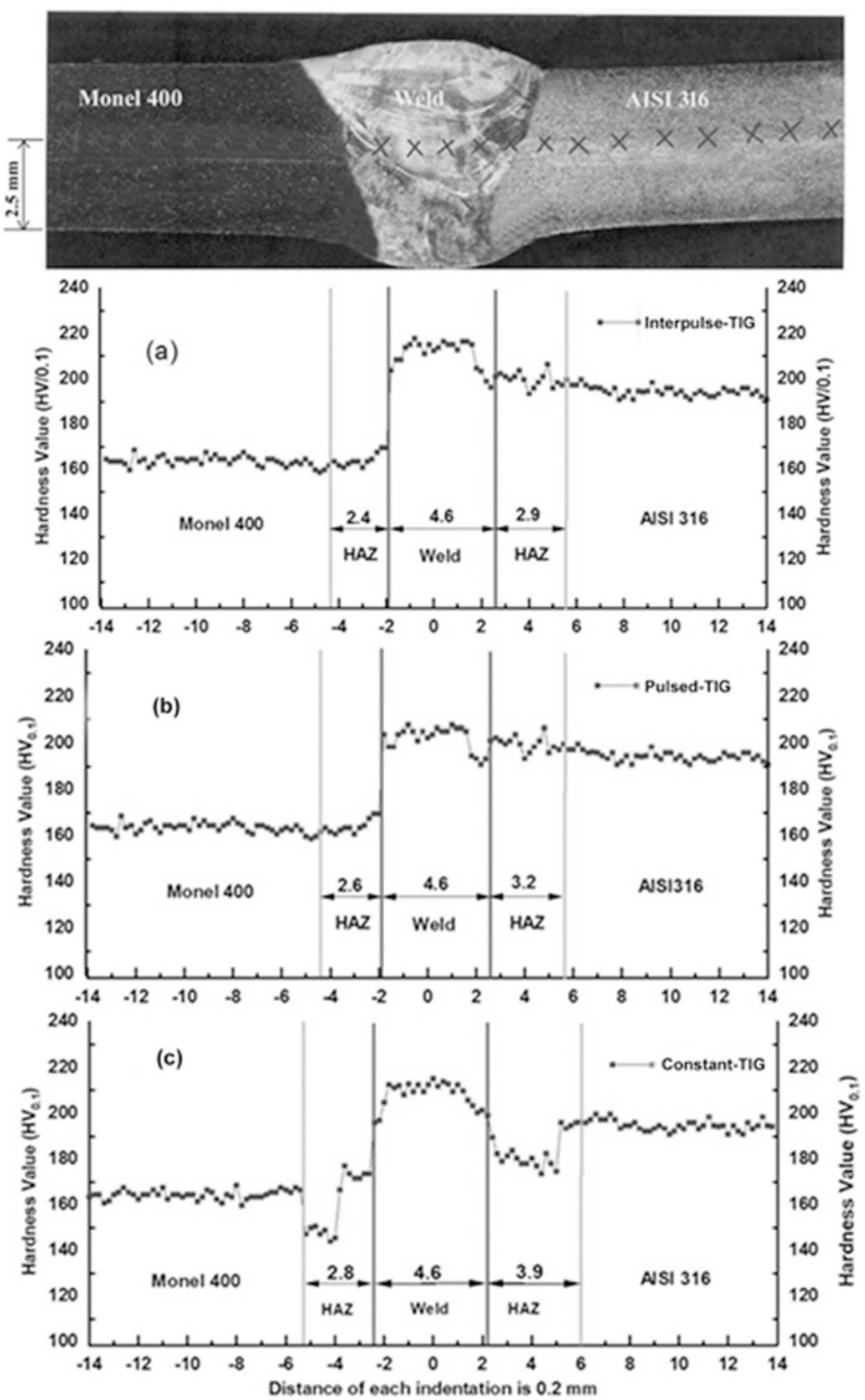

Fig. 5. Vickers microhardness profiles of (a) Interpulse TIG, (b) Pulsed TIG, (c) Constant TIG dissimilar weldments. 
B. Yelamasetti, G. Rajyalakshmi: Properties of dissimilar weldments of Monel 400 and AISI 316

Table 5. Comparison of width and average Vickers microhardness value of TIG, pulsed and Interpulse current TIG weldments.

\begin{tabular}{|c|c|c|c|c|c|c|}
\hline \multirow{2}{*}{ Welding technique } & \multicolumn{2}{|c|}{ Monel 400} & \multicolumn{2}{c|}{ Weld zone } & \multicolumn{3}{c|}{ AISI 316} \\
\cline { 2 - 7 } & HAZ (mm) & $\mathrm{HV}_{0.1}$ & Fusion $(\mathrm{mm})$ & $\mathrm{HV}_{0.1}$ & HAZ $(\mathrm{mm})_{1} \mathrm{HV}_{0.1}$ \\
\hline Constant-TIG & 2.8 & 155 & 4.6 & 212 & 3.9 & 184 \\
Pulsed-TIG & 2.6 & 163 & 4.6 & 208 & 3.2 & 202 \\
Interpulse-TIG & 2.4 & 172 & 4.6 & 215 & 2.9 & 204 \\
\hline
\end{tabular}

pulse TIG techniques due to controlled heat input rates, to which could be attributed the formation of fine grain structure near the fusion boundary. SEM/EDS analysis revealed the presence of main compositional elements such as nickel and iron at the weld zone, contributing towards the hardness of grains. The comparison was made of the heat affected region width and microhardness of three the weldments and results are listed in Table 5. The heat affected region was found to be narrower on both the base materials of Interpulse TIG welding technique compared to that of welded joints made using constant and pulsed current TIG welding techniques.
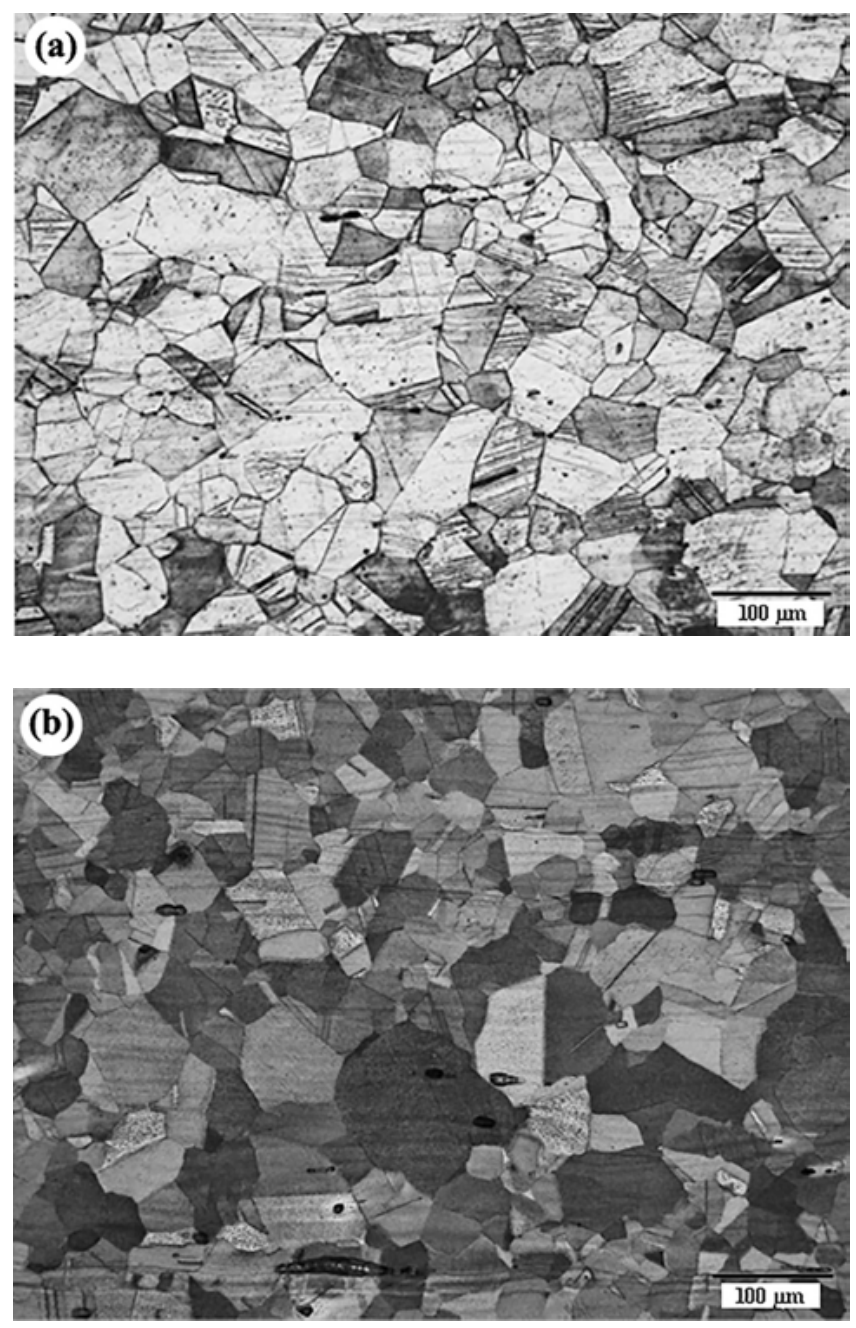

Fig. 6. Microstructures of base metals (a) Steel grade 316, (b) Monel 400 .

\subsection{Metallurgical studies}

\subsubsection{Base metals}

The base metals, steel grade 316 and Monel 400, microstructures are shown in Fig. 6. The austenitic grains of mechanically deformed grains were identified in the microstructure of AISI 316 as shown in Fig. 6a. Single phase solid solution nickel-copper enriched structures with annealed grain boundaries were identified in the microstructure of Monel 400, as shown in Fig. 6 b.

\subsubsection{Constant current TIG weldment}

Typical OM and SEM micrographs of various zones of AISI 316 and Monel 400 are shown in Fig. 7. It is observed that coarse grains were formed at the HAZ of both the base plates, which could be attributed due to continuous heat input rates. Migrated grain boundaries (MGBs) were also seen in the well-developed austenitic welds which emerged due to the reheating cycles during multiple passes. With the increase of heat input, the growth of substructures can also be clearly seen as a result of dislocation migration. The interface of steel grade 316 as shown in Fig. 7a and b reveals that the formation of clear grain boundaries and clear grain structures about 50 microns were observed in TIG weldments. The elemental micro-segregation of alloying elements was seen to have dark spots in the micro-graphs of Monel 400 interface as shown in Fig. 7c and d that might have been caused by differences in heating and cooling cycles. The weld zone of the TIG welded joint shows long dendritic structures and clear grain boundaries, as shown in Fig. 8, which could serve to increased hardness values at the weld zone. The addition of the elements from filler wire such as $\mathrm{Mo}$ and $\mathrm{Nb}$ has resulted in the expansion of the Ni-rich, face centered cubic lattice, further resulting in the net enhancement in the strength of the austenite phase. SEM/EDS analysis at the weld zone shown in Fig. 9 revealed that the fusion boundary was enriched with $\mathrm{Cr}, \mathrm{Ni}$, $\mathrm{Fe}$ and Mo. The intensity of the peaks of $\mathrm{Ni}, \mathrm{Cu}, \mathrm{Fe}, \mathrm{Cr}$ and Mo was observed.

\subsubsection{Pulsed current TIG weldment}

Typical OM and SEM micrographs of the Monel 400 interface and AISI 316 interface of pulsed current TIG weldments are shown in Fig. 10. No grain coarsening was identified near the HAZ of Monel 400 from Fig. 10a and b, which could be attributed to the controlled total heat input and low pulse frequency $(4 \mathrm{~Hz})$. Also, columnar and long dendritic structures were observed at the HAZ of Monel 400. Clear grain boundaries and fine grain structures were observed at the interface of steel grade 316, as shown in Fig. 10c 

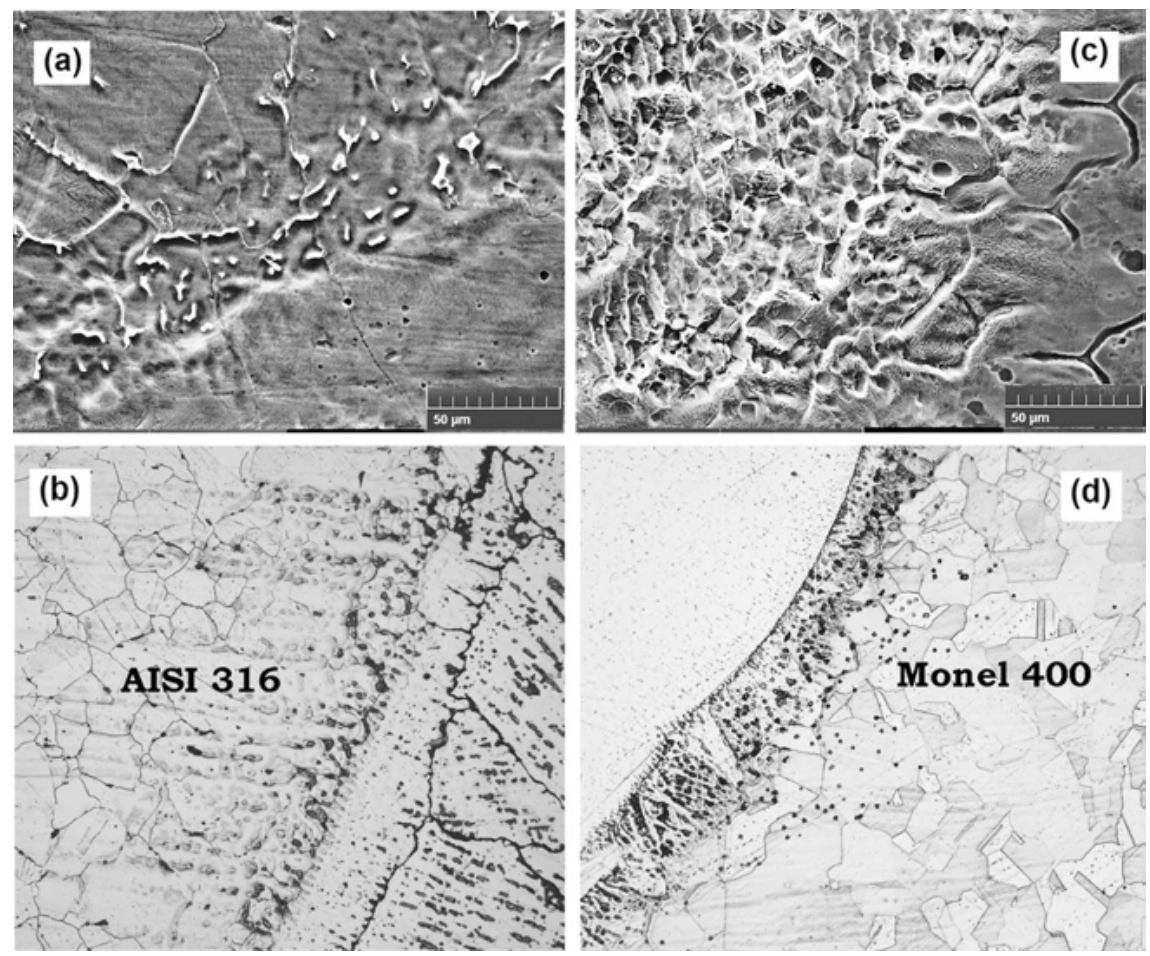

Fig. 7. SEM and OM micrographs of dissimilar TIG weldment (a, b) AISI 316, (c, d) Monel 400 .
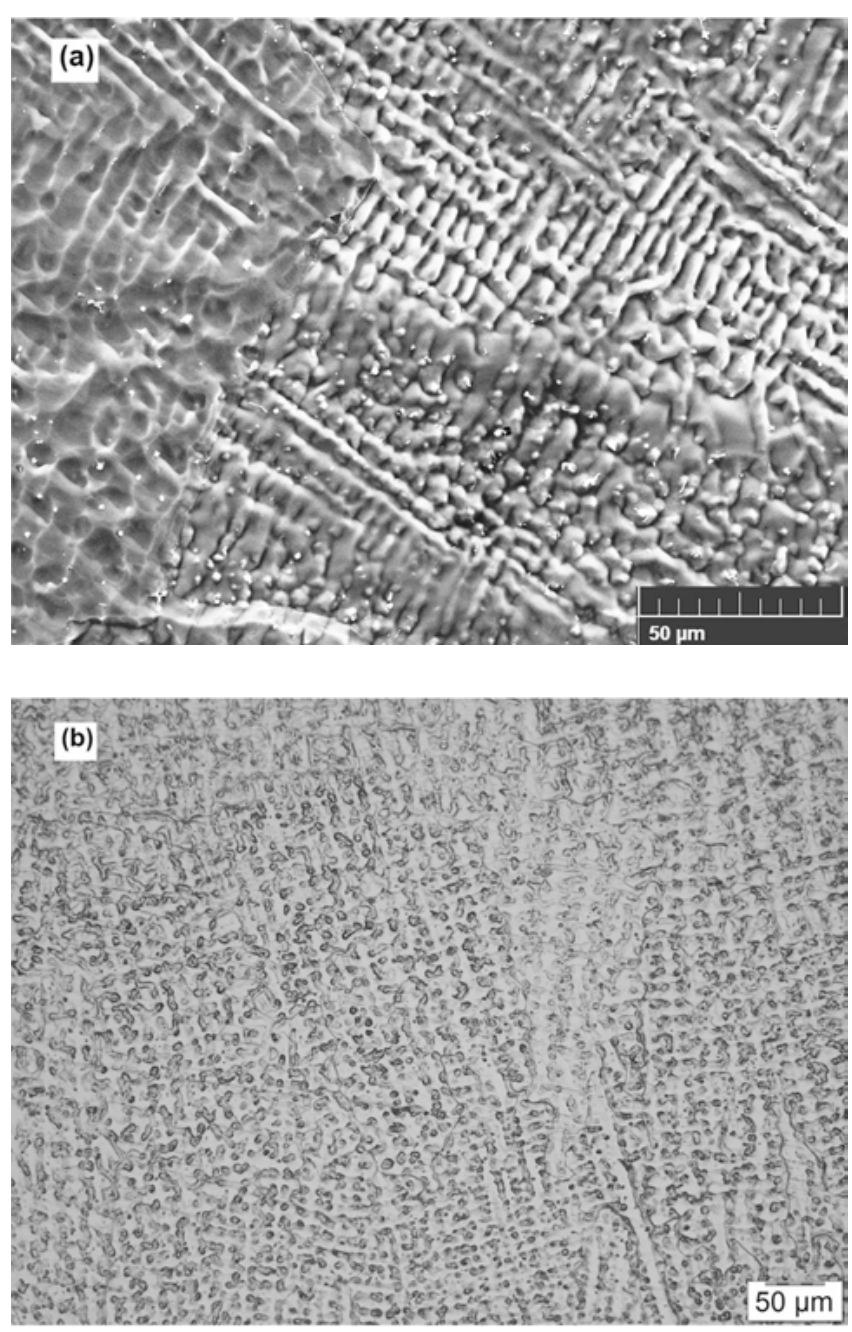

Fig. 8. ERNiCrMo-3 filler weld zone of dissimilar TIG weldment (a) SEM, (b) OM micrographs. and $\mathrm{d}$. The metallurgical studies also revealed that the fusion boundary has completely austenitic phase structures, as shown in Fig. 11. Secondary phase formation and isolation of alloying elements are greatly minimized in this welding technique. SEM/EDS analysis at the HAZ of Monel 400 and AISI 316 is shown in Fig. 12, which indicates that the weld boundary was enriched with $\mathrm{Fe}, \mathrm{Ni}, \mathrm{Mo}$ and $\mathrm{Cr}$. The intensity of the peaks of $\mathrm{Ni}, \mathrm{Cu}, \mathrm{Fe}, \mathrm{Cr}$ and $\mathrm{Mo}$ were observed.

\subsubsection{Interpulse current TIG weldment}

Typical OM and SEM micrographs of various zones of Interpulse TIG weldments of steel grade 316 and Monel 400 are shown in Fig. 13. The interface of Monel 400 in the Interpulse TIG weldment microstructure reveals well defined grain structures and equi-axed fine grain structure near the weld zone, as shown in Fig. 13a and b. Also, columnar and long dendritic structures were identified in the welded zone nearer to the interface of Monel 400. Grain refinement and grain boundaries, as shown in Fig. 13c and d, were formed near the weld zone at the interface of steel grade 316 due to the constricted arc and controlled heat input rates in the Interpulse TIG welding technique. The weld zone has completely austenitic phase structures, as shown in Fig. 14. Secondary phase formation and segregation of alloying elements are enormously controlled by utilizing an Interpulse welding process in welded joints. SEM/EDS analysis at the weld zone shown in Fig. 15 revealed that the fusion boundary was enriched with $\mathrm{Cr}, \mathrm{Ni}, \mathrm{Fe}$ and Mo. The intensity of the peaks of $\mathrm{Ni}$, $\mathrm{Cu}, \mathrm{Fe}, \mathrm{Cr}$ and Mo was observed. The segregation of alloying elements, of filler wire was not found at the interface of both the base plates. The minimized segregation of alloying elements, as observed from Fig. 15 for Interpulse TIG welding, is attributed with the increase in the yield 


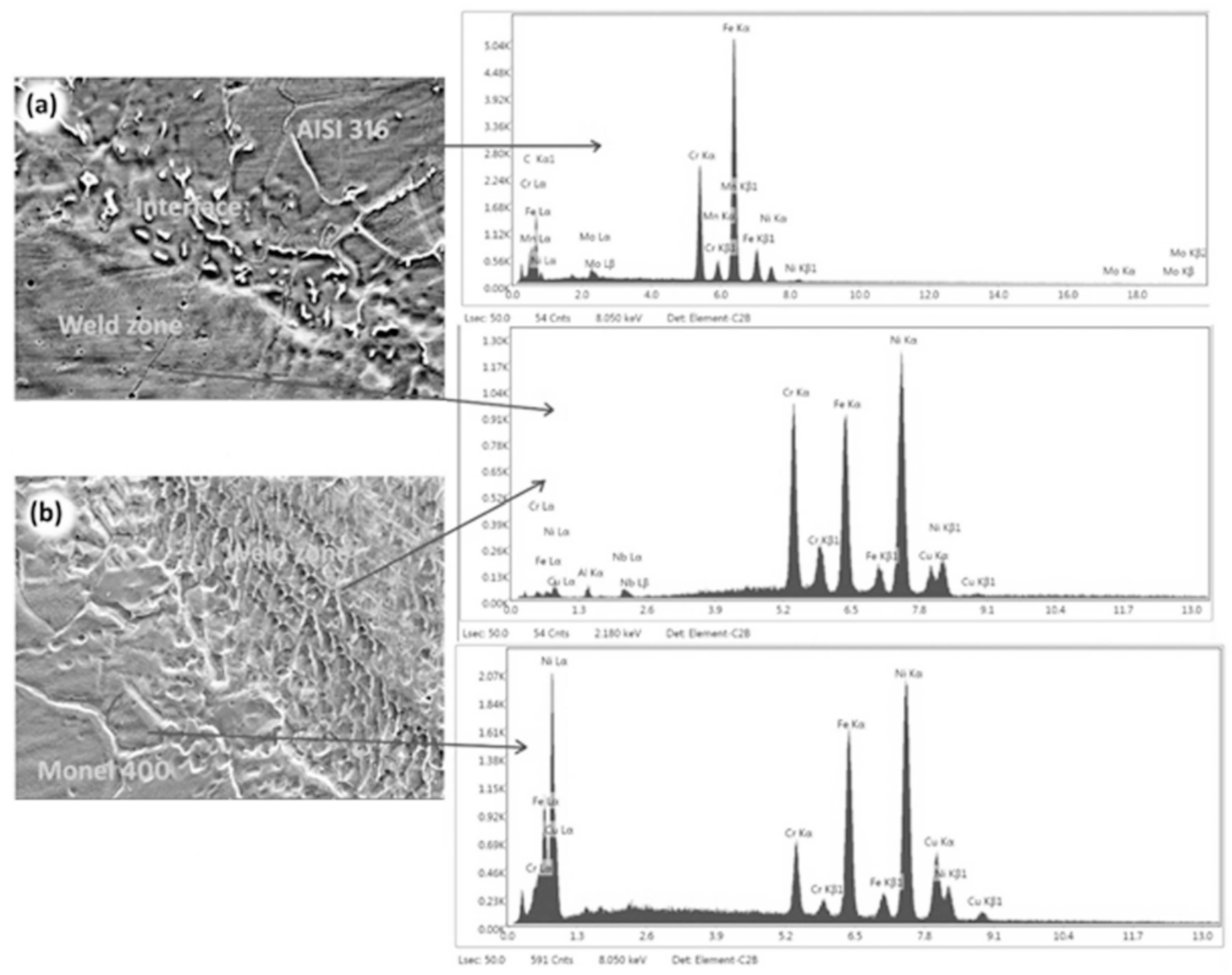

Fig. 9. SEM/EDS point analysis of dissimilar TIG weldment: (a) AISI 316, (b) Monel 400.
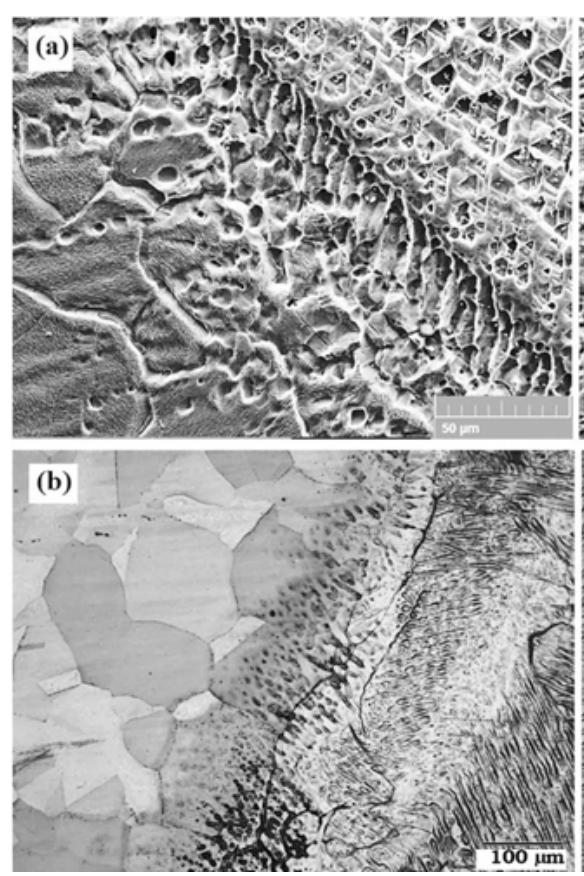
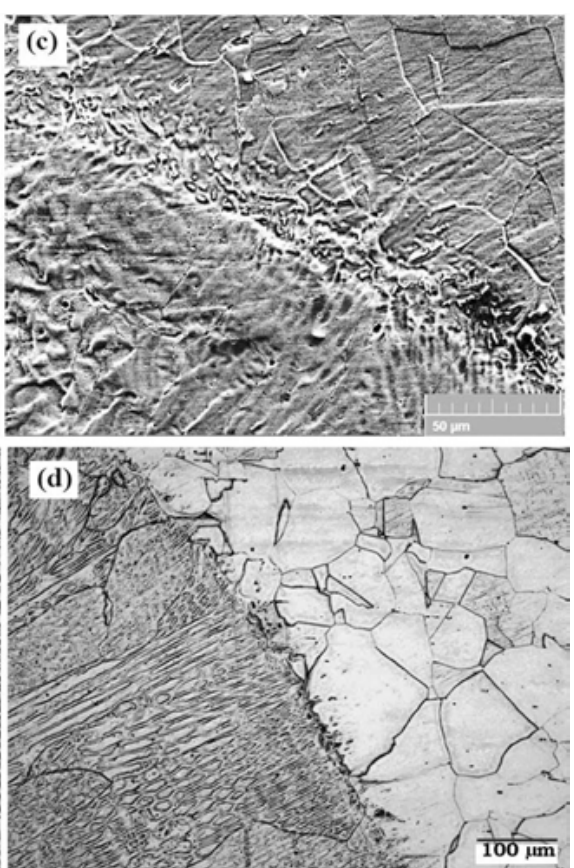

Fig. 10. SEM and OM micrographs of dissimilar pulsed TIG weldment: $(a, b)$ Monel 400, (c, d) AISI 316. 

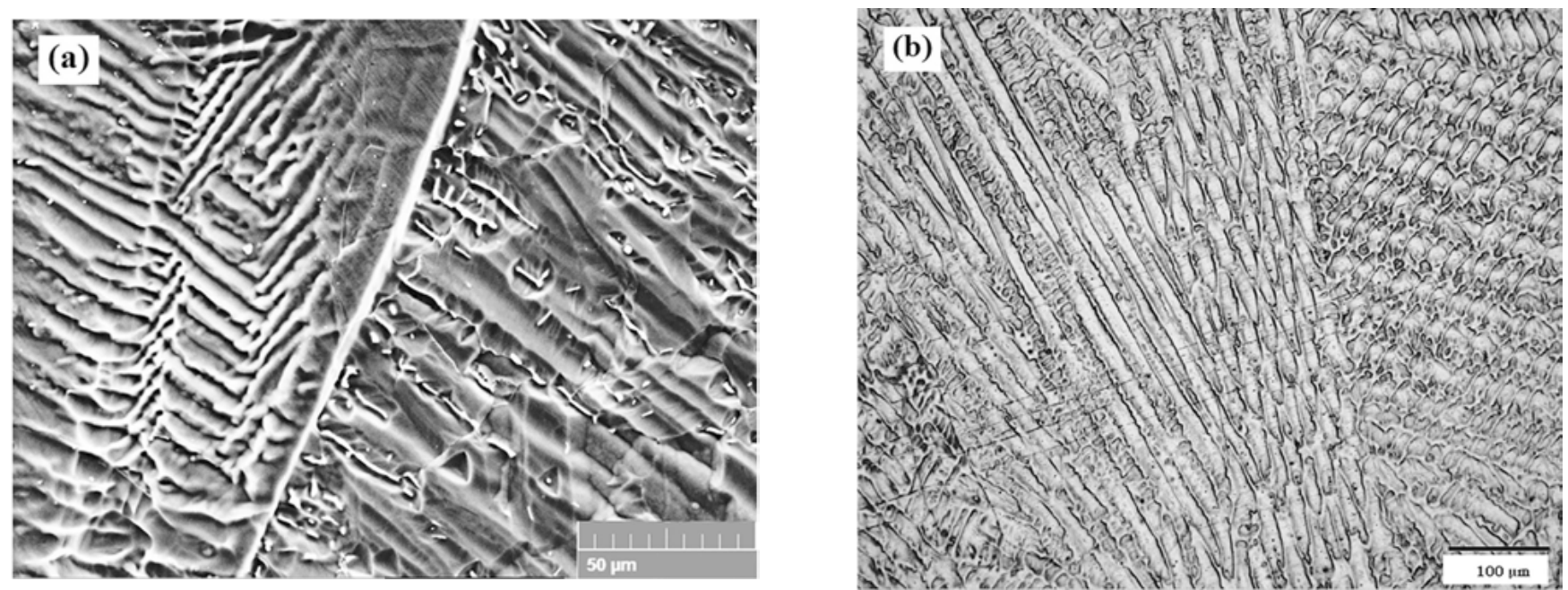

Fig. 11. Weld zone of dissimilar pulsed TIG weldment: (a) SEM, (b) OM micrographs.

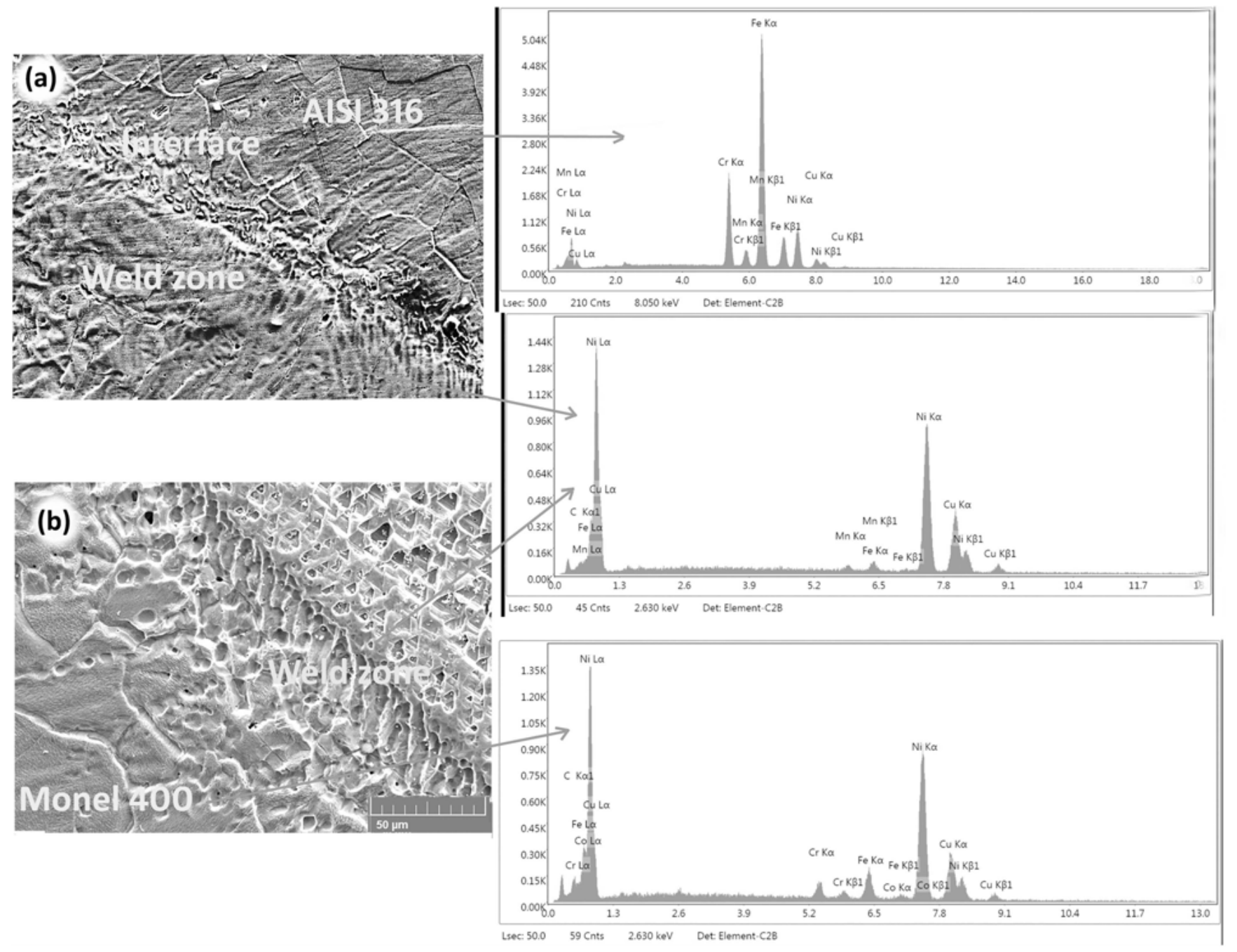

Fig. 12. SEM/EDS X-ray point analysis of dissimilar pulsed TIG weldment: (a) AISI 316, (b) Monel 400.

Int. J. Mater. Res. (formerly Z. Metallkd.) 111 (2020) 11 

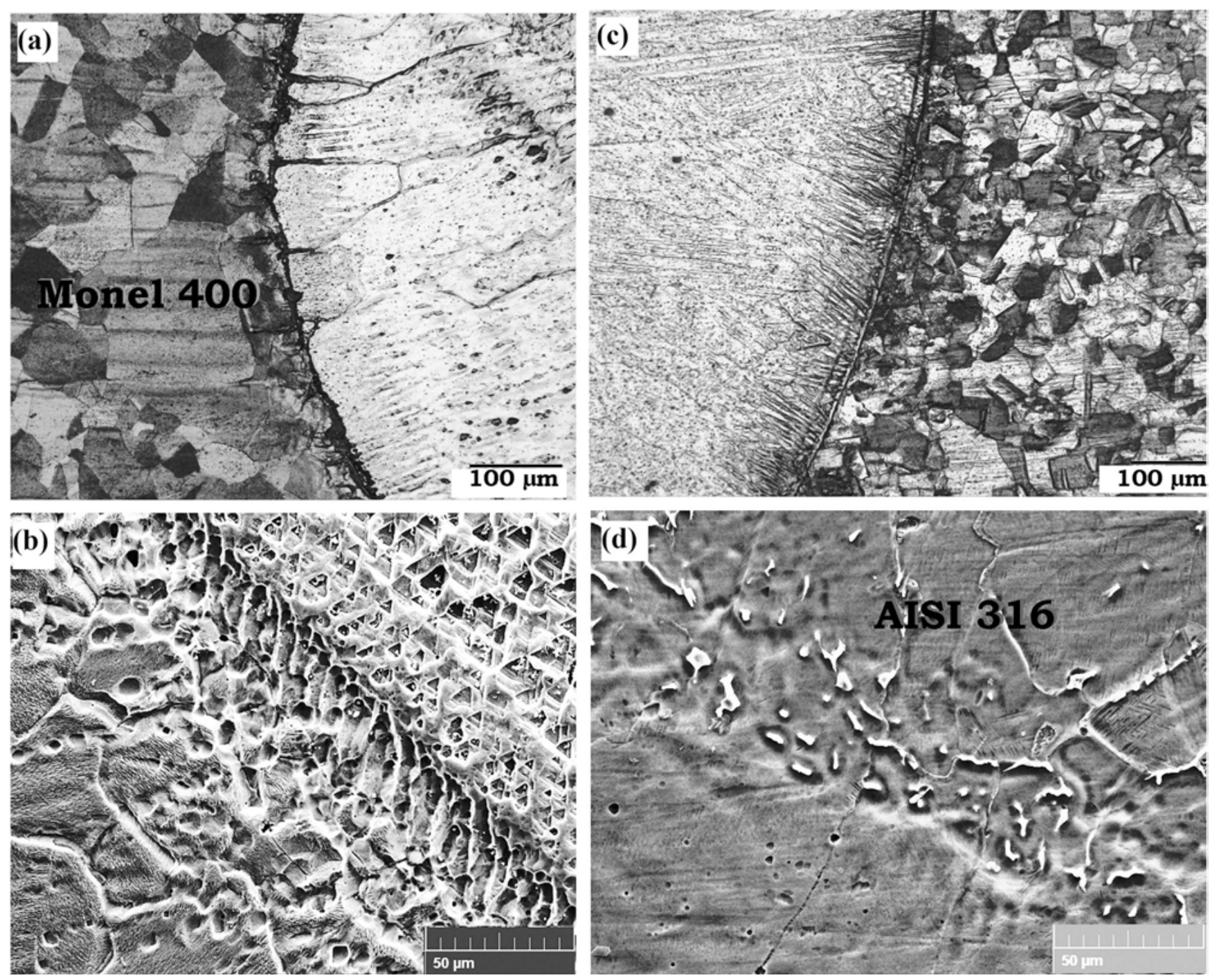

Fig. 13. OM and SEM HAZ microstructures of Interpulse TIG weldment: (a, b) Monel 400, (c, d) AISI 316.
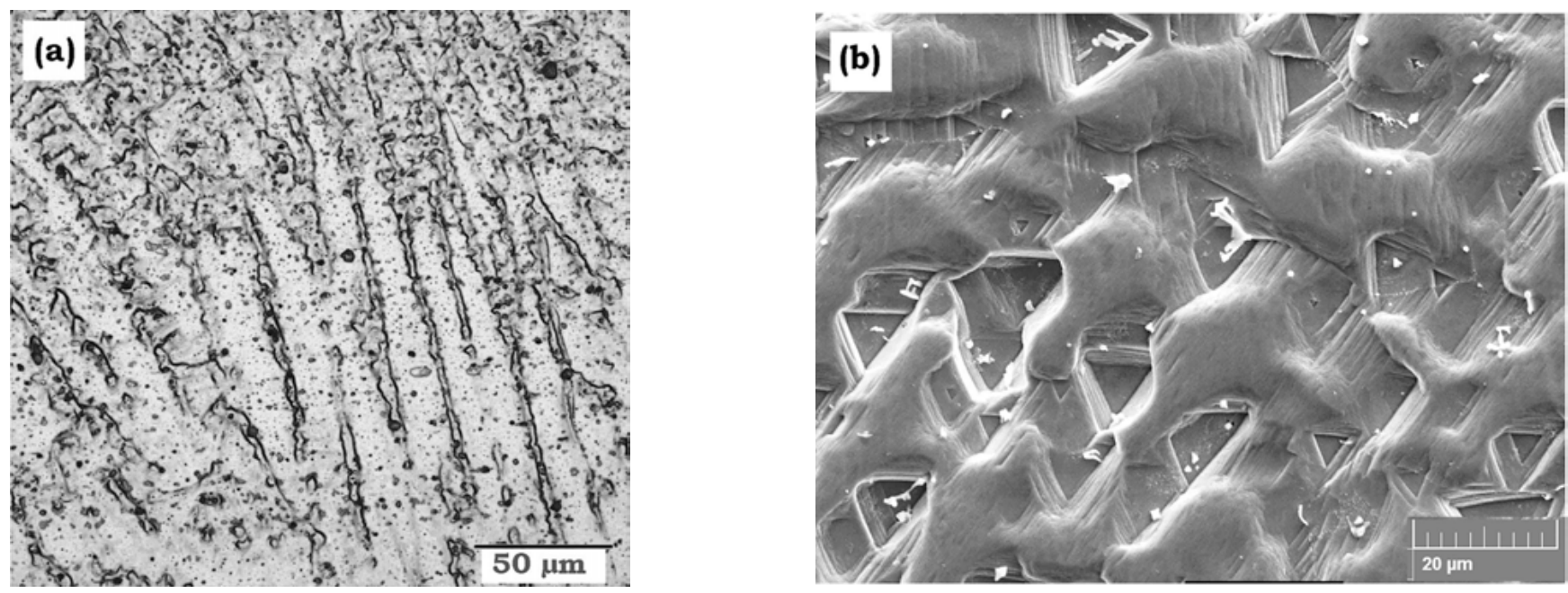

Fig. 14. Weld zone of dissimilar Interpulse TIG weldment: (a) OM, (b) SEM micrographs. 


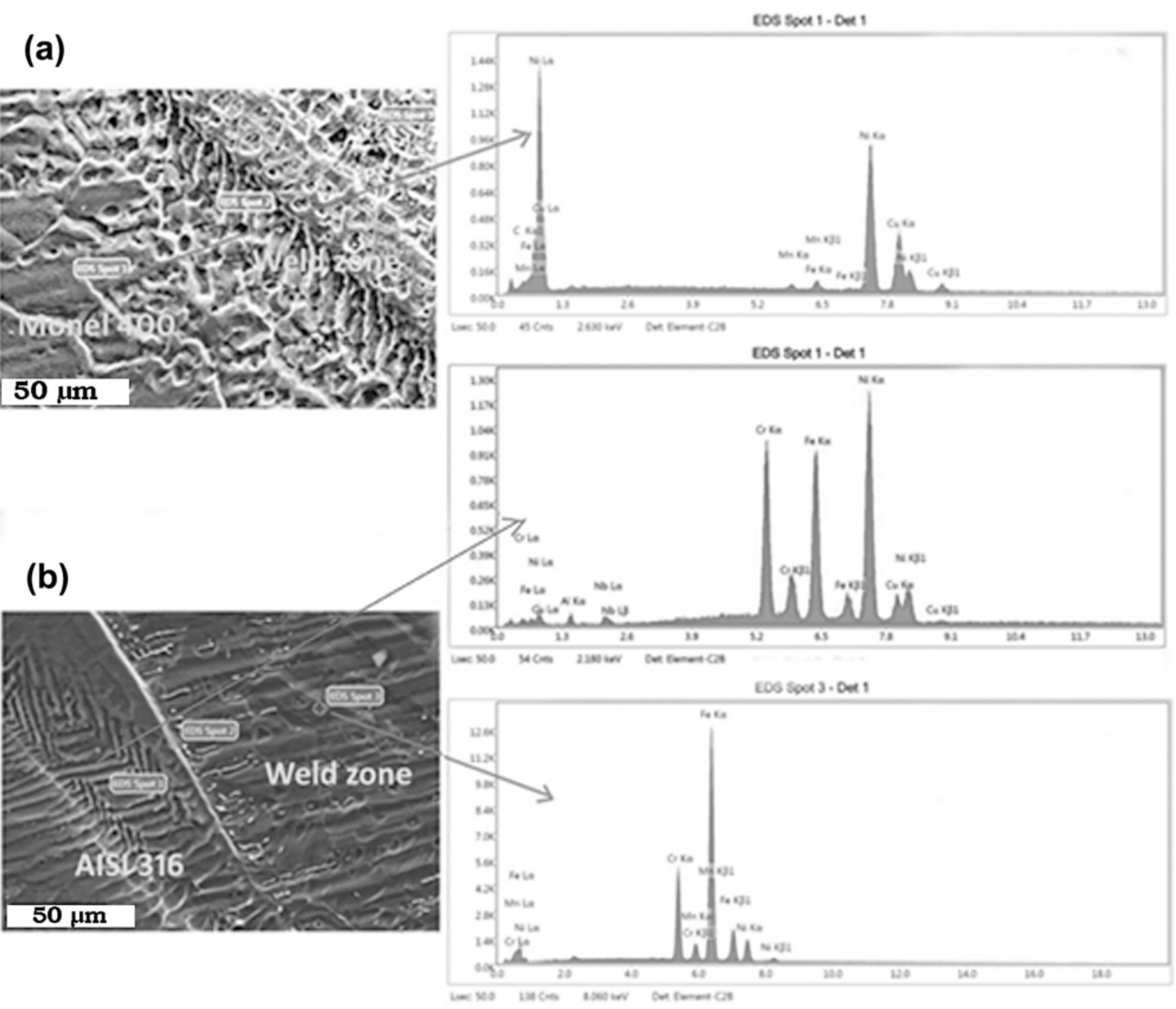

Fig. 15. SEM/EDS X-ray point analysis of dissimilar Interpulse TIG weldment: (a) Monel 400, (b) AISI 316.

strength. From the SEM/EDS point analysis, the chemical compositions of HAZ and weld zone of three dissimilar weldments are listed in Table 6 . In the three welding techniques, niobium $(\mathrm{Nb})$ alloying element was observed at the fusion zone which promotes the formation of carbides (NbC) during solidification which will improve the ductility dip cracking (DDC).

\section{Conclusion}

The constant, pulsed and Interpulse current TIG welding techniques have been used to join the dissimilar combination of AISI 316 and Monel 400 successfully by using ERNiCrMo-3 filler wire. The conclusions drawn from the experimental studies are as follows;

- The residual stresses of constant, pulsed and Interpulse current TIG welding techniques were found to be $189 \mathrm{MPa}, 101 \mathrm{MPa}$ and $53 \mathrm{MPa}$, respectively, and compressive in nature. The developed residual stresses in these welded structures were self-balanced and within the yield limits only. Due to the constricted arc heat input rates in the Interpulse TIG welding technique the residual stresses were reduced by $51.3 \%$ and $71.9 \%$ when compared to pulse and constant current TIG techniques, respectively.

- The weld strength and microhardness of the Interpulse current TIG weldment are superior than the other two welded joints. The weld strength of Interpulse current TIG welding technique was improved by $5.7 \%$ and $7.7 \%$ when compared to pulsed and constant current TIG welding techniques, respectively.

- The ratio of yield strength to that of ultimate tensile strength was higher in pulsed current TIG weldment (0.62) and Interpulse current TIG weldment (0.61) than in constant current TIG weldment (0.46).

- The microhardness of constant, pulsed and Interpulse current TIG dissimilar weldments at the weld zone is increased by $30.8 \%, 28.4 \%$ and $32.7 \%$, respectively when compared to the microhardness of base metal Monel 400.

- The HAZs on both sides of base metals were greatly reduced in Interpulse TIG welded joints compared to that of TIG welded joint. The HAZ width of Monel 400 and AISI 316 of Interpulse TIG weldment decreased by $14.28 \%$ and $25.64 \%$, respectively when compared to the constant current TIG weldment. 
B. Yelamasetti, G. Rajyalakshmi: Properties of dissimilar weldments of Monel 400 and AISI 316

Table 6. SEM/EDS point analysis (wt.\%) of dissimilar weldments joined by three welding techniques.

\begin{tabular}{|c|c|c|c|c|c|c|c|c|}
\hline \multicolumn{9}{|c|}{ (a) Constant-TIG } \\
\hline Zone & $\mathrm{Ni}$ & $\mathrm{Cr}$ & $\mathrm{Fe}$ & $\mathrm{Cu}$ & Mo & $\mathrm{Mn}$ & $\mathrm{Si}$ & Others \\
\hline Monel HAZ & 60.61 & 2.17 & 6.1 & 29.02 & 0.5 & 1.34 & 0.23 & - \\
\hline Weld zone & 47.21 & 20.06 & 18.42 & 9.01 & 2.2 & 1.71 & 0.2 & $\mathrm{Nb}-0.96, \mathrm{Al}-0.2$ \\
\hline AISI HAZ & 9.01 & 21.84 & 65.98 & - & 1.67 & 1.46 & - & - \\
\hline \multicolumn{9}{|c|}{ (b) Pulsed-TIG } \\
\hline Zone & $\mathrm{Ni}$ & $\mathrm{Cr}$ & $\mathrm{Fe}$ & $\mathrm{Cu}$ & Mo & $\mathrm{Mn}$ & $\mathrm{Si}$ & Others \\
\hline Monel HAZ & 61.93 & - & 4.17 & 32.17 & - & 1.37 & 0.34 & - \\
\hline Weld zone & 46.07 & 19.71 & 18.4 & 9.4 & 3.2 & 1.98 & 0.4 & $\mathrm{Nb}-0.79$ \\
\hline AISI HAZ & 9.31 & 18.74 & 68.69 & - & 1.24 & 1.96 & - & - \\
\hline \multicolumn{9}{|c|}{ (c) Interpulse-TIG } \\
\hline Zone & $\mathrm{Ni}$ & $\mathrm{Cr}$ & $\mathrm{Fe}$ & $\mathrm{Cu}$ & Mo & $\mathrm{Mn}$ & $\mathrm{Si}$ & Others \\
\hline Monel HAZ & 64.02 & - & 3.42 & 30.92 & - & 1.24 & 0.36 & - \\
\hline Weld zone & 47.04 & 20.01 & 19.02 & 7.05 & 3.8 & 2.01 & 0.3 & $\mathrm{Nb}-0.86$ \\
\hline AISI HAZ & 9.06 & 19.04 & 68.49 & - & 1.22 & 1.87 & - & - \\
\hline
\end{tabular}

- The segregation of alloying elements at the interface of base plates and coarse grain structures were observed with the constant current TIG welding technique. Whereas the segregation of alloying elements was controlled in the pulsed TIG welding technique. Grain refinement and well-defined grain boundaries were observed in welded joints obtained from Interpulse current TIG welding.

- The Interpulse current TIG welding resulted in considerably reduced residual stresses and improved mechanical and metallurgical properties owing to its controlled total heat input during the process which will help to prevent inter-granular stress corrosion cracking.

\section{References}

[1] J.R. Davis: ASM Specialty Handbook, Epub ahead of print, USA (2000). (2000). DOI:10.1361/ncta2000p013,

[2] J.N. DuPont, J.C. Lippold, S.D. Kiser: John Wiley \& Sons, Inc., New Jersey. (2009) 53. DOI:10.1017/CBO9781107415324.004

[3] J.C. Lippold, D.J. Kotecki: Wiley-Interscience, John Wiley \& Sons, Inc., New Jersey (2005).

[4] K.D. Ramkumar, S.V. Naren, P.V.R. Karthik, A. Tiwari, N. Arivazhagan: J. Manuf. Process. (2016). DOI:10.1016/j.jmapro.2015.10.004

[5] Y. Balram, G. Rajyalakshmi: Mater. Res. Express. (2019). DOI: $10.1088 / 2053-1591 / a b 23 c f$

[6] K.D. Ramkumar, A. Chandrasekhar, A.K. Singh, S. Ahuja, N. Arivazhagan: Metallogr. Microstruct. Anal. (2015). DOI:10.1007/s13632-015-0236-y

[7] Yelamasetti. Balram, Kumar. Sravan, B. Sridhar, T. Vishnu, V.R. Gunda: Mater.Today Proc. (2019). DOI:10.1016/j.matpr.2019.06.759

[8] K.D. Ramkumar, A. Chandrasekhar, A. Srivastava, H. Preyas, S. Chandra, S. Dev, N. Arivazhagan: J. Manuf. Process. (2016). DOI:10.1016/j.jmapro.2016.07.006

[9] K.D. Ramkumar, N. Arivazhagan, S. Narayanan: Mater. Des. (2012). DOI:10.1016/j.matdes.2012.03.024

[10] P.J. Withers, H.K.D.H Bhadeshia: Mater. Sci. Technol. (2001). DOI: $10.1179 / 026708301101509980$

[11] O. Anderoglu: Residual Stress Measurement Using X-Ray Diffraction, Texas A\&M Univ. (2004) 64.

[12] P.S. Prevey: Met. Handbook, Met. Park (1986) 513. DOI:10.1361/asmhba0001761
[13] S.A.A. Akbari, R. Miresmaeili: J. Mater. Process. Technol. (2008) 208. DOI:10.1016/j.jmatprotec.2008.01.015

[14] Y. Balram, G. Rajyalakshmi: U.P.B. Sci. Bull., Ser. D. (2018) 80

[15] D. Deng, H. Murakawa, W. Liang: Comput. Methods Appl. Mech. Eng. (2007) 196. DOI:10.1016/j.cma.2007.05.023

[16] P. Vasantharaja, V. Maduarimuthu, M. Vasudevan, P. Palanichamy: Mater. Manuf. Process. (2012) 27. DOI: $10.1080 / 10426914.2012 .663135$

[17] A.R. Kohandehghan, S. Serajzadeh, A.H. Kokabi: (2010) 25. DOI: $10.1080 / 10426914.2010 .481004$

[18] Z. Zhang, Y. Feng, Q. Tan, J. Zou, J. Li, X. Zhou, G. Sun, Y. Wang: (2019) 166. DOI:10.1016/j.matdes.2019.107603

[19] I.I. Ahmed, J.A. Adebisi, S. Abdulkareem, A.H. Sherry: J. King Saud Univ. - Eng. Sci. (2018) 30. DOI:10.1016/j.jksues.2016.01.004

[20] Y. Javadi, M. Ashoori M: Vessel. Mater. Des. (2015) 85. DOI:10.1016/j.matdes.2015.07.012

[21] T. Bajpei, H. Chelladurai, M.Z. Ansari: J. Manuf. Process. (2017) 25. DOI:10.1016/j.jmapro.2016.12.017

[22] S. Murugan, S.K. Rai, P.V. Kumar, T. Jayakumar, B. Raj, M.S.C. Bose: (2001) 78. DOI:10.1016/S0308-0161(01)00047-3

[23] E. Ranjbarnodeh, S. Serajzadeh, K.A. Hosein, S. Hanke, A. Fischer: Int. J. Adv. Manuf. Technol. (2011) 55. DOI:10.1007/s00170-010-3095-3

[24] V. Harinadh, G. Edison, A. Suresh, B.R. Kumar: Int. J. Eng. Technol. (2018) 7. DOI:10.14419/ijet.v7i4.10.20711

[25] D. Deng, H. Murakawa, W. Liang: Comput. Mater. Sci. (2008) 42. DOI:10.1016/j.commatsci.2007.07.009

[26] S. Pandit, V. Joshi, M. Agrawal, M. Manikandan, K.D. Ramkumar, N. Arivazhagan, S. Narayanan: Procedia Eng. (2014) 75. DOI:10.1016/j.proeng.2013.11.012

[27] K.D. Devendranath, N. Arivazhagan, S. Narayanan: Kov. Mater. (2014) 52. DOI: $10.4149 / \mathrm{km}-2014-5-287$

[28] Y. Balram, G. Rajyalakshmi, G.V. Ramana, B. Sridhar, V. Harinadh: Int. J. Adv. Manuf. Technol. (2020) 108. DOI: 10.1007/s00170-020-05562-w

[29] K.D. Ramkumar, G. Thiruvengatam, S.P. Sudharsan, D. Mishra, N. Arivazhagan, R. Sridhar: Mater. Des. (2014) 60. DOI:10.1016/j.matdes.2014.03.031

[30] S. Pichumani, R. Srinivasan, V. Ramamoorthi: J. Mech. Sci. Technol. (2018) 32. DOI:10.1007/s12206-018-0130-4

[31] S. Avinash, Y. Balram, B. Sridhar, G. Venkatramana: Mater. Today Proc. (2019). DOI:10.1016/j.matpr.2019.07.211

[32] S. Dev, K.D. Ramkumar, N. Arivazhagan, R. Rajendran: J. Manuf. Process. (2018) 32. DOI:10.1016/j.jmapro.2018.03.035 
[33] K.D. Ramkumar, V. Joshi, S. Pandit, M. Agrawal, O.S. Kumar, S. Periwal, M. Manikandan, N. Arivazhagan: Mater. Des. (2014) 64. DOI:10.1016/j.matdes.2014.08.055

[34] G.M. Reddy, A.A. Gokhale, K.P. Rao: Mater. Sci. Technol. (1998) 14. DOI:10.1179/mst.1998.14.1.61

[35] Y. Balram, G. Rajyalakshmi: Mater. Today Proc. (2019). DOI:10.1016/j.matpr.2019.08.125

[36] D. Mishra, A. Manjunath, K. Parthiban: Ind. Welding Journal. (2017) 50. DOI:10.22486/iwj/2017/v50/i4/162271

[37] P.N. Kumar, Y. Bhaskar, P. Mastanaiah, C.V.S. Murthy: Procedia Mater. Sci. (2014) 5. DOI:10.1016/j.mspro.2014.07.483

[38] Y. Balram, T.V. Vardhan, G.V. Ramana: Proc. Inst. Mech. Eng. Part C J. Mech. Eng. Sci. (2020). DOI:10.1177/0954406220960780

[39] P.K. Giridharan, N. Murugan: Int. J. Adv. Manuf. Technol. (2009) 40. DOI: $10.1007 / \mathrm{s} 00170-008-1373-0$

[40] M. Fitzpatrick, A. Fry, P. Holdway, F. Kandil, J. Shackleton, L. Suominen: Meas. Good Pract. Guid. (2005) 74. DOI:10.1007/s00028-005-0194-y

(Received March 1, 2020; accepted August 6, 2020)

\section{Correspondence address}

Balram Yelamasetti

Assistant Professor

Full Postal Adress: Department of Mechanical Engineering

CMR Institute of Technology

Medchal

Hyderabad-501401

Telangana

India

Tel.: +919951312204

E-mail: balram3072@gmail.com

\section{Bibliography}

DOI 10.3139/146.111961

Int. J. Mater. Res. (formerly Z. Metallkd.)

111 (2020) 11; page 880-893

(C) Carl Hanser Verlag GmbH \& Co. KG

ISSN 1862-5282 